Ensino, Saúde e Ambiente - V.10 (2), pp. 16-38, Ago. 2017

\title{
O RIO POMBA SOB O OLHAR DOS ALUNOS DO ENSINO FUNDAMENTAL, SEGUNDO SEGMENTO, EM DUAS ESCOLAS MUNICIPAIS DE SANTO ANTÔNIO DE PÁDUA/RJ
}

\section{THE POMBA RIVER UNDER THE LOOK OF STUDENTS OF FUNDAMENTAL TEACHING, SECOND SEGMENT, IN TWO MUNICIPAL SCHOOLS OF SANTO ANTÔNIO DE PÁDUA/RJ}

\author{
Marcelo Nocelle de Almeida ${ }^{1}$, Thayná Machado Pereira ${ }^{2,3}$, Andryelle Christine Maia \\ Almeida $^{2,3}$, Caroline Coutinho Carneiro Freitas ${ }^{2}$, Ana Carla de Oliveira Faria ${ }^{2}$ \\ ${ }^{1}$ Universidade Federal Fluminense (UFF)/Departamento de Ciências Exatas, Biológicas e da \\ Terra/mnocelle@id.uff.br \\ ${ }^{2}$ Universidade Federal Fluminense/Graduandas do curso de Licenciatura em Ciências Naturais \\ ${ }^{3}$ Programa Licenciatura-2016/Divisão de Prática Discente/Universidade Federal Fluminense
}

\section{RESUMO}

A identificação das representações sociais que os alunos trazem auxilia o planejamento de práticas pedagógicas transformadoras e não apenas repetitivas. As representações sociais também são a base para elaboração de projetos de educação ambiental. $O$ objetivo desse trabalho foi investigar e compreender a representação social que o rio Pomba apresenta para os alunos de ensino fundamental de duas escolas do município de Santo Antônio de Pádua/RJ. O trabalho foi desenvolvido através da evocação livre de palavras e desenhos livres. Houve diferença entre as representações dos alunos das duas escolas pesquisadas. Os alunos da escola localizada na zona rural possuem uma representação naturalista do rio, enquanto os alunos da escola localizada na zona urbana possuem uma representação globalizante, principalmente calcada na poluição do rio.

Palavras-chave: Representação social, representação do meio ambiente, educação ambiental.

\begin{abstract}
The identification of the social representations that the students bring helps the planning of transformative and not only repetitive pedagogical practices. Social representations are also the basis for the elaboration of environmental education projects. The objective of this work was to investigate and understand the social representation that the Pomba River presents for elementary school students from two schools in the municipality of Santo Antônio de Pádua/RJ. The work was developed through free evocation of free words and drawings. There was a difference between the representations of the students of the two schools surveyed. The students of the school located in the countryside have a naturalistic representation of the river, while the students of the school located in the urban zone have a globalizing representation, mainly based on the pollution of the river.
\end{abstract}

Key words: Social representation, Representation of the environment, environmental education. 


\section{Ensino, Saúde e Ambiente - V.10 (2), pp. 16-38, Ago. 2017}

\section{INTRODUÇÃO}

Questões ambientais associadas à preservação da qualidade de vida da população urbana têm sido cada vez mais debatidas nos âmbitos sociais, políticos e acadêmicos (BARROS; BARATA, 2009; SILVA et al., 2014), principalmente em direção a adoção de práticas que visem à sustentabilidade e a diminuição dos impactos que as atividades humanas tem provocada nos ecossistemas (ROOS; BECKER, 2012). Seguramente, o principal mecanismo para adquirirmos essa condição de equilíbrio é a educação ambiental. Contudo, é preciso romper a barreira da educação ambiental conservadora. Essa vertente consiste na perpetuação do modelo de desenvolvimento capitalista e industrial, que é importante, conforme destacou Roos e Becker (2012), mas também é necessária uma maneira de obter o desenvolvimento com sustentabilidade.

Por outro lado, a vertente da educação ambiental emancipatória busca uma sociedade que caminha em direção à igualdade e à justiça socioambiental, conforme destacou Líbera e Jurberg (2013). Essa afirmação encontra apoio na linha de raciocínio de Lutzemberg (1980) e Capra (1998), ao descreverem que a educação ambiental é um fenômeno múltiplo e que envolve aspectos físicos, sociais, econômicos, culturais, políticos, históricos e éticos. Podemos resumir todos esses aspectos em um só termo, cidadania, conforme preconiza as orientações contidas nos Parâmetros Curriculares Nacionais, educação para formar cidadãos (BRASIL, 1997).

No entendimento de Silva (2009), cabe a educação formal embasar reflexões sobre o meio ambiente, com objetivo de formar cidadãos aptos para aquisição de valores, tomadas de decisões e atitudes condizentes com o ambiente e a sociedade. Ainda sobre a educação ambiental, Reigota (2010, p. 14) salientou que o conhecimento das representações sociais deve anteceder o processo de formação em educação ambiental, pois, o autor acrescenta ainda que por ser uma representação social, o conceito de meio ambiente depende da formação das pessoas, de suas experiências e do lugar onde vivem (REIGOTA, 1991).

O conceito de representação coletiva nas Ciências Sociais foi desenvolvido inicialmente por Émile Durkheim em 1897, em sua obra "O suicídio". Modernamente, Moscovici, em 1961, passa a denominar essas representações de sociais, e não mais coletivas. Ainda segundo Durkheim (op. cit.), as representações coletivas influem nas decisões tomadas individualmente (REIGOTA, 2010).

Segundo Mazzotti (1997), Moscovici não tinha interesse em verificar se as representações sociais eram uma correta exposição das teorias científicas. Outros sim, 


\section{Ensino, Saúde e Ambiente - V.10 (2), pp. 16-38, Ago. 2017}

para Moscovici, as representações sociais organizavam as condutas e atitudes das pessoas, e, portanto, eram verdadeiras para quem as construiu. Mazzotti (1997) continua afirmando que a representação social não é consensual e apresenta divergências em torno de um núcleo central. Assim, a investigação das representações sociais tem por objetivo fundamental a explicitação do núcleo central. $\mathrm{O}$ autor afirmou ainda que a definição do núcleo central permita agir para alterar a representação. Dessa forma, torna-se relevante para a educação e outras práticas sociais a modificação das condutas dos grupos sociais.

Na mesorregião noroeste fluminense, o rio Pomba ainda hoje é uma importante fonte de subsistência e renda para muitas famílias, sobretudo aquelas de baixa renda que sobrevive da pesca. No município de Santo Antônio de Pádua/RJ, o rio Pomba sofre com ações humanas desde o período colonial quando se iniciou a retirada da mata ciliar para o plantio da cana-de-açúcar, posteriormente o café, e, atualmente, a pecuária. Outros problemas são o lançamento de efluentes domésticos e industriais, além da introdução de espécies exóticas, principalmente peixes.

Sobre esse aspecto, Bezerra et al. (2008) afirmaram que a descrição dos conhecimentos e sentimentos da população em relação ao ambiente em que vive pode representar uma ferramenta estratégica para monitorar e fomentar mudanças de atitudes nos grupos socioculturais (professores do entorno, alunos e familiares, proprietários de terra, pesquisadores e administração). Nessa mesma linha de raciocínio, Pereira et al. (2016), ressaltaram que o estudo da percepção ambiental é importante para a compreensão da relação entre o homem a o ambiente em que vive. Completam afirmando que entender o que indivíduo percebe sobre o meio em que vive, ajuda a criar mecanismo de melhoria para o mesmo.

A utilização da teoria das representações sociais como mote central desse trabalho decorre das considerações de Gallo (2000), dizendo que a formação do aluno não ocorre através da assimilação de discursos, e sim por um processo micro social, que o leva a assumir posturas de liberdade, respeito e responsabilidade, mas também quando percebe essas mesmas práticas nos demais membros que participam do seu relacionamento cotidiano. Reforçando e complementando essa idéia, para Almeida (2005 apud SILVA; TEIXEIRA, 2015) o estudo de uma representação social presume investigar o que pensam, por que pensam e como pensam os indivíduos acerca de um determinado objeto. 


\section{Ensino, Saúde e Ambiente - V.10 (2), pp. 16-38, Ago. 2017}

Esse trabalho objetivou investigar a percepção que os alunos do sexto ano do ensino fundamental possuem sobre o rio Pomba? Essa proposta de investigação encontrou apoio nas palavras de Sauvé e Orellana (2001), onde as autoras afirmaram que o ambiente é uma realidade complexa, multidimensional, tendo um caráter difuso e variado. Dessa forma, procuramos investigar quais aspectos do rio Pomba são importantes, relevantes e socialmente representativos para os alunos. Essas questões são fundamentais para a elaboração de estratégias didáticas e pedagógicas no campo da educação ambiental emancipatória.

Assim, o objetivo desse trabalho foi investigar e compreender as representações sociais do rio Pomba em alunos do ensino fundamental, segundo segmento, em duas escolas públicas de Santo Antônio de Pádua/RJ.

\section{MATERIAL E MÉTODOS}

\section{CARACTERIZAÇÃO DA ÁREA DE ESTUDO}

O município de Santo Antônio de Pádua/RJ, localizado na mesorregião noroeste fluminense tem hoje como atividades industriais que mais se destacam as indústrias de papéis e pedras ornamentais. Essas indústrias empregam o maior número de pessoas do município e região, contudo, deixam suas marcas na paisagem, sendo a principal elas a retirada da floresta tropical.

O rio Pomba nasce na Serra Conceição (cadeia da Mantiqueira) no município de Barbacena/MG. Desde a nascente até sua foz no Rio Paraíba do Sul no município de Itaocara/RJ corre por cerca de $305 \mathrm{~km}$, tendo como principais afluentes os rios Novo, Piau, Xopotó, Formoso e Pardo. Possui uma área de drenagem de $8.616 \mathrm{~km}^{2}$ e abrange 35 municípios mineiros e três municípios fluminenses, com uma população de aproximadamente 450 mil habitantes.

Esse trabalho foi realizado nas Escolas Municipais Manoel Miguel Souto (EMMS), localizada no Distrito de Campelo, distante cerca de 13,0 $\mathrm{Km}$ do centro da cidade, e na Escola Municipal Escola Viva (EV), localizada no Bairro Mirante, ambas no município de Santo Antônio de Pádua/RJ. Participaram do trabalho 77 alunos, sendo 20 da EMMS, dos quais 12, 03 e 05 alunos eram do $6^{\circ}, 7^{\circ}$ e $8^{\circ}$ ano, respectivamente. Na EV participaram 57 alunos do $6^{\circ}$ ano, sendo 27 da turma 600 e 30 da turma 601.

A metodologia seguiu duas fases: a primeira ocorreu por meio da evocação livre de palavras e a segunda por meio de desenhos livres. A utilização de mais de uma 


\section{Ensino, Saúde e Ambiente - V.10 (2), pp. 16-38, Ago. 2017}

técnica, segundo Garrido e Meirelles (2014), permite o confrontamento de dados e confere uma validade maior às informações coletadas.

\section{EVOCAÇÃO LIVRE DE PALAVRAS}

A técnica de evocação livre de palavras foi realizada conforme Ferreira et al. (2005), Cortes Jr. et al. (2009) e Magalhães Jr. e Tomanik (2012, 2013). Inicialmente, os alunos foram convidados a escrever as cinco primeiras palavras que lhe vinham à mente a partir do termo indutor "rio Pomba". Em seguida, foi solicitado que os alunos classificassem as palavras de acordo com o grau de importância, atribuindo "1" para a palavra considerada mais importante, "2" para a segunda palavra mais importante e assim sucessivamente até " 5 " para a menos importante. A análise das palavras evocadas foi feita em três etapas: a) categorização das palavras em grupos semânticos; b) cálculo da frequência de ocorrência dos grupos semânticos; e c) cálculo da ordem média de evocação (OME).

Segundo Ferreira et al. (2005), o agrupamento das palavras evocadas em grupos semânticos é importante para evitar que expressões similares sejam consideradas como distintas. Foram desconsideradas as palavras com frequência unitária, uma vez que, de acordo com esses mesmos autores, a representação só é social quando compartilhada por um conjunto de sujeitos.

$\mathrm{O}$ cálculo da frequência dos grupos semânticos (FGS) foi feito somando-se o número de vezes em que a palavra foi citada pelos alunos. A ordem média de evocação (OME) considerou o número de vezes e a posição em que a palavra foi citada. Esse cálculo foi feito a partir da fórmula citada por Ferreira et al. (2005), e está ilustrado no Quadro 1. Foi utilizado como exemplo o grupo semântico "pedra" da Escola Manoel Miguel Souto. O cálculo da ordem média de evocação de cada um dos demais grupos semânticos em ambas as escolas seguiu a mesma metodologia ilustrada no Quadro 1.

Por último, os grupos semânticos foram organizados em Tabelas com quatro quadrantes, onde foram identificados os elementos que compõem o núcleo central $\left(1^{\circ}\right.$ quadrante), núcleos intermediários ( $2^{-}$e $3^{\circ}$ quadrantes) e o núcleo periférico $\left(4^{\circ}\right.$ quadrante) das representações (FERREIRA et al., 2005; CORTES Jr. et al., 2009; MAGALHÃES Jr.; TOMANIK, 2012, 2013). 
Ensino, Saúde e Ambiente - V.10 (2), pp. 16-38, Ago. 2017

Quadro 1: Cálculo da freqüiência e da ordem média de evocação do grupo semântico "pedra" da Escola Municipal Manoel Miguel Souto.

\begin{tabular}{|c|}
\hline Exemplo: grupo semântico "pedra" \\
\hline Número de vezes que foi evocada e hierarquizada em $1^{\circ}$ lugar: 1 \\
Número de vezes que foi evocada e hierarquizada em $2^{\circ}$ lugar: 1 \\
Número de vezes que foi evocada e hierarquizada em $3^{\circ}$ lugar: 4 \\
Número de vezes que foi evocada e hierarquizada em $4^{\circ}$ lugar: 7 \\
Número de vezes que foi evocada e hierarquizada em $5^{\circ}$ lugar: 1 \\
\hline Frequência total: $1+1+4+7+1=14$ \\
\hline Cálculo da OME: [(1 x 1$)+(1 \times 2)+(4 \times 3)+(7 \times 4)+(1 \times 5)] / 14=3,43$ \\
\hline
\end{tabular}

Fonte: Adaptado de Ferreira et al. (2005).

\section{DESENHOS}

Educadores e pesquisadores da educação em ciências tem cada vez mais valorizado as imagens como parte integrante da construção e comunicação dos conceitos científicos (CAPPELLE e MUNFORD, 2015). Ainda segundo essas autoras, a produção de imagens nos primeiros anos do ensino fundamental é bastante estimulada, porém, com o passar do tempo, as imagens perdem espaço em detrimento da escrita.

Dessa forma, na segunda fase do trabalho foi solicitado aos alunos que representassem livremente o rio Pomba por meio de um desenho. Cada aluno recebeu uma folha de papel A4, lápis preto e lápis de cor para a confecção dos desenhos. A análise dos desenhos foi realizada de forma quantitativa e qualitativa. $\mathrm{Na}$ análise quantitativa cada desenho foi incluído em uma categoria, sendo que para delimitá-las foram revisados diversos autores que utilizaram essa metodologia, Reigota (1991), Sauvé (2005), Rezler et al. (2009), Reigota (2010) e Líbera e Jurberg (2013). Optou-se por utilizar as categorias empregadas por Sauvé (2005) e Rezler et al. (2009), as quais estão expostas a seguir:

(a) Ambiente preservado: conjunto de elementos que se inter-relacionam formando uma unidade em um espaço que, tendo sofrido ou não a interferência humana, não possui vestígios de degradação ou contaminação química e/ou biológica. Desenhos que incluíram apenas elementos naturais bióticos e/ou abióticos.

(b) Ambiente não preservado: conjunto de elementos que se inter-relacionam formando uma unidade em um espaço que sofreu algum tipo de degradação e/ou contaminação química e/ou biológica pela interferência humana. 


\section{Ensino, Saúde e Ambiente - V.10 (2), pp. 16-38, Ago. 2017}

(c) Ambiente construído: espaço contendo um conjunto de elementos feitos pelo homem que se inter-relacionam formando uma unidade, podendo possuir elementos naturais. Desenhos que incluíram construções humanas, sem, contudo, degradar o ambiente.

(d) Ambiente como recurso: desenhos que incluíram a presença de recursos naturais ligados à sobrevivência e utilidade para humanos.

A análise quantitativa comparou por meio do teste do qui-quadrado (com nível de significância de 5\%), as frequências de desenhos em cada categoria e em cada escola. Para a análise qualitativa, cada desenho foi observado individualmente, onde se procurou identificar as partes e elementos que o compunham, e por fim o desenho como um todo. Essa sequência permitiu uma melhor compreensão da representação do rio sob a forma de desenho (GALVÃO et al., 2016).

Os dados relativos a evocação livre de palavras e aos desenhos foram obtidos sob total anonimato de seus autores, como forma de garantir a privacidade dos participantes.

\section{RESULTADOS E DISCUSSÃO}

\section{EVOCAÇÃO LIVRE DE PALAVRAS}

$\mathrm{Na}$ Escola Manoel Miguel Souto foram evocadas 32 palavras, entre as quais 21 foram excluídas, por se tratarem de evocações unitárias. Nas turmas 600 e 601 da Escola Viva foram evocadas 47 e 65 palavras, respectivamente, contudo, foram utilizadas na análise 20 e 28, descartando-se as demais pela mesma razão anterior. A análise das palavras evocadas permitiu reuni-las em 12 grupos semânticos de palavras, conforme demonstrado na Tabela 1. Os dados ausentes em determinados grupos semânticos foram em função da exclusão das evocações unitárias.

Cabe aqui uma ressalva em relação à elaboração dos grupos semânticos. No grupo semântico Fauna foi incluída evocações referentes aos répteis e aves. Optou-se por excluir desse grupo semântico evocações referentes aos peixes, uma vez que esse grupo faunístico possui elevada importância na alimentação e lazer da região (pesca esportiva), refletida por elevada frequência de evocação, como pode ser observado na Tabela 1.

A partir da Ordem Média de Evocações (Tabela 1) foram construídas as Tabelas 2, 3 e 4, onde estão representados os núcleos centrais, intermediários e 


\section{Ensino, Saúde e Ambiente - V.10 (2), pp. 16-38, Ago. 2017}

periféricos das Escolas Manoel Miguel Souto, Escola Viva (turmas 600 e 601), respectivamente.

Tabela 1: Frequência de evocação dos grupos semânticos e da ordem média de evocação das palavras na Escola Manoel Miguel Souto (EMMS) e na Escola Viva (EV), turmas 600 e 601.

\begin{tabular}{lcccccc}
\hline \multirow{2}{*}{$\begin{array}{c}\text { Grupo semântico palavras } \\
\text { Água }\end{array}$} & \multicolumn{2}{c}{ Frequência de evocação } & \multicolumn{3}{c}{ OME } \\
\cline { 2 - 7 } & EMMS & EV/600 & EV/601 & EMMS & EV/600 & EV/601 \\
\hline Areia & 07 & 16 & 15 & 1,86 & 2,06 & 2,2 \\
Dimensão & 12 & - & - & 3,17 & - & - \\
Embarcação & 03 & - & 11 & 2,67 & - & 2,54 \\
Fauna & 02 & - & - & 3,5 & - & - \\
Flora & 04 & 02 & 02 & 3,5 & 2,5 & 4,0 \\
Meio ambiente & - & - & 02 & - & - & 4,0 \\
Pedra & - & 05 & 12 & - & 3,2 & 2,84 \\
Peixe & 14 & 08 & 02 & 3,43 & 4,13 & 3,5 \\
Percepção & 14 & 13 & 08 & 1,43 & 2,77 & 3,25 \\
sensorial & - & 09 & 22 & - & 2,22 & 3,09 \\
Ponte & & & & & & \\
Poluição & - & 02 & 02 & - & 5,0 & 4,5 \\
\hline Total & 08 & 53 & 43 & 5,0 & 3,09 & 2,81 \\
Média & 64 & 108 & 119 & 24,56 & 24,97 & 32,73 \\
\hline
\end{tabular}

Fonte: Os autores.

O núcleo central de evocações na Escola Manoel Miguel Souto foi o elemento peixe. Conforme dito anteriormente, esse item é muito freqüente na alimentação e no lazer da comunidade onde se localiza a escola. Os integrantes da comunidade convivem desde a infância, com as histórias e com o hábito da pesca no rio Pomba, evidenciando assim, a elevada importância desse elemento para os alunos.

A frequência do grupo semântico pedra foi idêntica ao grupo peixe, contudo, foi evocado em posições inferiores ao grupo anterior, o que determinou sua inclusão como elemento intermediário ( $2^{\underline{o}}$ quadrante). Baixo valor da OME indica que a palavra foi evocada e hierarquizada em posição superior. A elevada frequência do grupo semântico pedras, se deve ao aspecto paisagístico da localização da escola. A ponte sobre o rio Pomba que dá acesso ao distrito de Campelo está apoiada sobre uma constituição rochosa muito evidente (Figura 1A). O local é muito utilizado para o lazer da comunidade local, o que foi determinante para sua alta frequência de evocação. Na comunidade onde se localiza a escola, a extração de areia é uma atividade comercial 


\section{Ensino, Saúde e Ambiente - V.10 (2), pp. 16-38, Ago. 2017}

relevante, o que proporcionou a inclusão desse grupo semântico como elemento intermediário ( $2^{\circ}$ quadrante).

Como elementos periféricos ( $4^{\underline{0}}$ quadrante) foram incluídos dois itens que merecem destaque, poluição e embarcação. O trecho do rio Pomba que banha a comunidade ainda não se encontra poluído, pois, seguindo o curso do rio, Campelo se situa antes da zona urbana do município, onde o rio recebe a maior carga de efluentes. Na localidade a extração de areia é uma atividade comercial, o que foi determinante para a criação do grupo semântico embarcação (palavras: bote - 1 evocação, máquina de puxar areia - 2 evocações), para essa escola (Tabela 1). Contudo, esse grupo semântico, embarcação, foi inserido no $4^{\underline{0}}$ quadrante (Tabela 2 ), caracterizando-o como elemento periférico.

A Escola Viva fica localizada próxima ao limite das zonas rural e urbana do município, exatamente onde o rio começa a receber os efluentes domésticos e industriais. Dessa forma, a palavra com maior frequência de evocação nessa escola foi poluição (Tabelas 3 e 4), sendo essa uma característica muito evidente nessa porção do rio. Na turma 601 houve um contraste peculiar no núcleo central, pois, as palavras limpo, bonito, saudável e pureza, que constituem o grupo semântico "percepção sensorial", ocupou a segunda maior freqüência (22 evocações), indicando que enquanto alguns alunos percebem o rio como poluído, outros o enxergam com beleza. Uma palavra muito frequente em ambas as turmas da Escola Viva foi enchente. É muito comum durante a estação chuvosa na região, o transbordamento do rio Pomba em Santo Antônio de Pádua, fazendo com que essa situação seja uma representação muito forte na vida da população do município. A palavra enchente foi a principal contribuição para a freqüência do grupo semântico “água” como elemento central na Escola Viva.

Não houve elementos intermediários no $2^{\underline{0}}$ quadrante da turma 600 da Escola Viva (Tabela 3), em função da frequência e da ordem média de evocação (Tabela 1). Os três grupos semânticos incluídos no $3^{\circ}$ quadrante tiveram frequências distintas, porém, os valores das OMEs foram semelhantes, o que permite afirmar que esses grupos foram hierarquizados em posições semelhantes. Na turma 601 houve semelhança nas frequências e OMEs entre os grupos semânticos incluídos no $2^{\underline{o}}$ e $3^{\underline{o}}$ quadrantes, indicando que esses grupos semânticos de palavras representam elementos intermediários para a comunidade. Em ambas as turmas, o grupo semântico peixe foi incluído no $3^{\mathrm{o}}$ quadrante, caracterizando-o como elemento intermediário, e não tendo a mesma representação e importância, quando comparado com a outra escola. 
Tabela 2: Composição do núcleo central, intermediários e periféricos das representações sociais na Escola Municipal Manoel Miguel Souto, localizada no Distrito de Campelo, município de Santo Antônio de Pádua/RJ.

\begin{tabular}{|c|c|c|c|c|c|}
\hline \multicolumn{3}{|c|}{$\begin{array}{c}\text { Elementos centrais }-1^{\circ} \text { quadrante } \\
\text { Alta f e baixa OME } \\
\text { f }>8,0 \text { e OME }<3,07\end{array}$} & \multicolumn{3}{|c|}{$\begin{array}{c}\text { Elementos intermediários - } 2^{-} \text {quadrante } \\
\text { Alta f e alta OME } \\
\text { f }>8,0 \text { e OME } \geq 3,07\end{array}$} \\
\hline Grupo semântico de palavras & $\mathrm{f}$ & OME & Grupo semântico de palavras & $\mathrm{f}$ & OME \\
\hline \multirow{2}{*}{ Peixe } & 14 & 1,43 & Pedra & 14 & 3,43 \\
\hline & & & Areia & 12 & 3,17 \\
\hline \multicolumn{3}{|c|}{$\begin{array}{c}\text { Elementos intermediários - } 3^{\circ} \text { quadrante } \\
\text { Baixa f e baixa OME } \\
\mathrm{f}<8,0 \text { e OME }<3,07\end{array}$} & \multicolumn{3}{|c|}{$\begin{array}{c}\text { Elementos periféricos - } 4^{\mathrm{o}} \text { quadrante } \\
\text { Baixa f e alta OME } \\
\mathrm{f}<8,0 \text { e OME } \geq 3,07\end{array}$} \\
\hline Grupo semântico de palavras & $\mathrm{f}$ & OME & Grupo semântico de palavras & $\mathrm{f}$ & OME \\
\hline Água & 7 & 1,86 & Poluição & 8 & 5,0 \\
\hline \multirow[t]{2}{*}{ Dimensão } & 3 & 2,67 & Fauna & 4 & 3,5 \\
\hline & & & Embarcação & 2 & 3,5 \\
\hline
\end{tabular}

Fonte: Os autores.

Figura 1: (A) Ponte Vereador Edward de Abreu Campanário que liga o distrito de Paraoquena ao distrito de Campelo.

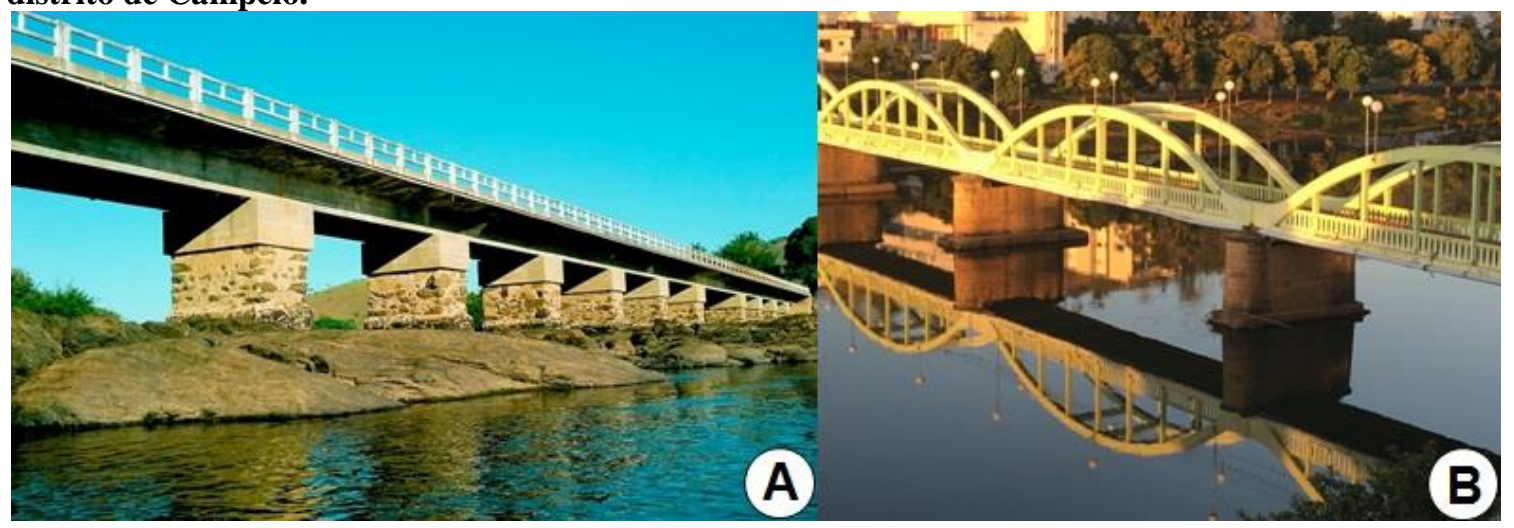

Fontes: (A) Andryelle Christine Maia Almeida; (B) Pablo de Vargas Guimarães.

Tabela 3: Composição do núcleo central, intermediários e periféricos das representações sociais na Escola Municipal Escola Viva, localizada no Bairro Mirante, município de Santo Antônio de Pádua/RJ, Turma 600.

Elementos centrais $-1^{\underline{0}}$ quadrante

$$
\text { Alta f e baixa OME }
$$

f $>13,5$ e $\mathrm{OME}<3,12$

Grupo semântico de f OME palavras

Poluição Água

Elementos intermediários - 3-o quadrante

Baixa f e baixa OME

$\mathrm{f}<13,5$ e $\mathrm{OME}<3,12$

Grupo semântico de

$53 \quad 3,09$

$16 \quad 2,06$

f OME
Elementos intermediários - $2^{\underline{0}}$ quadrante Alta $f$ e alta OME

f > 13,5 e $\mathrm{OME} \geq 3,12$

Grupo semântico de palavras f $\mathrm{OME}$
Elementos periféricos - $4^{0}$ quadrante

Baixa f e alta OME

$\mathrm{f}<13,5$ e OME $\geq 3,12$

Grupo semântico de palavras f OME 
Ensino, Saúde e Ambiente - V.10 (2), pp. 16-38, Ago. 2017

palavras

Peixe

Percepção sensorial

Fauna

\begin{tabular}{cc}
13 & 2,77 \\
9 & 2,22 \\
2 & 2,5 \\
\hline
\end{tabular}

Pedra
Meio ambiente
Ponte

84,13

$5 \quad 3,2$

Fonte: Os autores.

O grupo semântico pedra foi incluído no $4^{\circ}$ quadrante, caracterizando-o como elemento periférico pela turma 600. Embora haja algumas formações rochosas no trecho urbano do rio Pomba em Santo Antônio de Pádua, essa característica paisagística não ter a mesma relevância para esses alunos, o que contrasta com a representação desse grupo semântico para os alunos da Escola Manoel Miguel Souto.

Por último, observou-se que os grupos semânticos fauna, flora e meio ambiente possuem pequena representação para os alunos das escolas pesquisadas. Apenas para a turma 601 da Escola Viva, meio ambiente foi incluído como elemento intermediário ( $2^{\circ}$ quadrante), e fauna e flora foram incluídos como elementos periféricos. Na outra turma dessa mesma escola, assim como na Escola Manoel Miguel Souto, esses elementos não apresentaram relevante representação. Uma possível explicação seria o rio não ser visto como um meio ambiente que abriga uma rica fauna, bem como não se encontra atualmente margeado por matas ciliares. O entorno do Distrito de Campelo encontra-se muito desmatado, restando apenas poucos e pequenos fragmentos de vegetação. As margens do rio Pomba entre Campelo e Santo Antônio de Pádua apresentam também raros e pequenos trechos de mata ciliar. O conjunto desses fatores nos leva a acreditar que os alunos não consideram o rio como um ambiente rico em flora e fauna.

Tabela 4: Composição do núcleo central, intermediários e periféricos das representações sociais na Escola Municipal Escola Viva, localizada no Bairro Mirante, município de Santo Antônio de Pádua/RJ, Turma 601.

\begin{tabular}{|c|c|c|c|c|c|}
\hline \multicolumn{3}{|c|}{$\begin{array}{c}\text { Elementos centrais }-1^{\mathrm{o}} \text { quadrante } \\
\text { Alta f e baixa OME } \\
\mathrm{f}>11,9 \text { e OME }<3,27\end{array}$} & \multicolumn{3}{|c|}{$\begin{array}{c}\text { Elementos intermediários - } 2^{0} \text { quadrante } \\
\text { Alta f e alta OME } \\
\mathrm{f}>11,9 \text { e OME } \geq 3,27\end{array}$} \\
\hline $\begin{array}{c}\text { Grupo semântico de } \\
\text { palavras }\end{array}$ & $\mathrm{f}$ & OME & Grupo semântico de palavras & $\mathrm{f}$ & OME \\
\hline Poluição & 43 & 2,81 & & & \\
\hline Percepção sensorial & 22 & 3,09 & Meio ambiente & 12 & 2,84 \\
\hline Água & 15 & 2,2 & & & \\
\hline \multicolumn{3}{|c|}{$\begin{array}{c}\text { Elementos intermediários }-3^{\text {o }} \text { quadrante } \\
\text { Baixa f e baixa OME } \\
\mathrm{f}<11,9 \text { e OME }<3,27\end{array}$} & \multicolumn{3}{|c|}{$\begin{array}{c}\text { Elementos periféricos - } 4^{-} \text {quadrante } \\
\text { Baixa f e alta OME } \\
\mathrm{f}<11,9 \text { e OME } \geq 3,27\end{array}$} \\
\hline $\begin{array}{c}\text { Grupo semântico de } \\
\text { palavras }\end{array}$ & $\mathrm{f}$ & OME & Grupo semântico de palavras & $\mathrm{f}$ & OME \\
\hline
\end{tabular}


Ensino, Saúde e Ambiente - V.10 (2), pp. 16-38, Ago. 2017

\begin{tabular}{ccc|ccc} 
Dimensão & 11 & 2,54 & Fauna & 2 & 4,0 \\
Peixe & 8 & 3,25 & Flora & 2 & 4,0 \\
& & & Pedra & 2 & 3,5 \\
& & & Ponte & 2 & 4,5 \\
\hline
\end{tabular}

Fonte: Os autores.

\section{DESENHOS}

\section{ANÁLISE QUANTITATIVA}

A análise quantitativa dos desenhos feitos pelos alunos em ambas as escolas permitiu construir a Tabela 5. A freqüência de desenhos em cada categoria na Escola

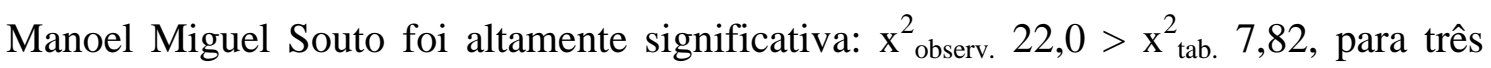
graus de liberdade. Por outro lado, na Escola Viva, em ambas as turmas, 600 e 601, o teste do qui-quadrado não foi significativo, sendo que os dados demonstraram uma distribuição mais homogênea na turma 600 , uma vez que o $x^{2}{ }_{\text {observ. }} 1,55<x_{\text {tab. }}^{2}, 99$, para dois graus de liberdade, e, na turma $601 \mathrm{o} \mathrm{x}^{2}{ }_{\text {observ. }} 5,0<\mathrm{x}_{\text {tab. }}^{2} 5,99$, também para dois graus de liberdade.

Tabela 5: Frequência de desenhos em cada categoria nas Escolas Manoel Miguel Souto (EMMS) e na Escola Viva (EV), turmas 600 e 601.

\begin{tabular}{lccc}
\hline \multicolumn{1}{c}{ Categorias } & \multicolumn{3}{c}{ Escolas } \\
\cline { 2 - 4 } \multicolumn{1}{c}{ dos desenhos } & EMMS & EV/600 & EV/601 \\
\hline $\begin{array}{l}\text { Ambiente preservado } \\
\text { Ambiente não }\end{array}$ & 02 & 11 & 10 \\
preservado & 01 & 10 & 15 \\
Ambiente construído & 14 & 06 & 05 \\
Ambiente como recurso & 03 & - & - \\
Total & 20 & 27 & 30 \\
\hline
\end{tabular}

Fonte: Os autores.

\section{ANÁLISE QUALITATIVA}

\section{AMBIENTE PRESERVADO}

Esperava-se que houvesse um número maior de desenhos representando o rio Pomba como um ambiente preservado na Escola Manoel Miguel Souto (Tabela 5). Contudo, apenas dois desenhos o representaram dessa forma, pois, no distrito onde se localiza a escola o rio ainda se encontra preservado (Figura 2A). Na turma 600 da 


\section{Ensino, Saúde e Ambiente - V.10 (2), pp. 16-38, Ago. 2017}

Escola Viva houve um equilíbrio entre as representações de ambiente preservado e não preservado, o mesmo não se repetindo na turma 601 (Tabela 5).

A vegetação nas margens do rio foi a principal representação entre os desenhos que o caracterizaram como um ambiente preservado em ambas as turmas da Escola Viva (Figura 2B, C e D). Essa representação é diferente da realidade das margens do rio Pomba na zona urbana do município, uma vez que são poucos os trechos com vegetação. De acordo com Líbera e Jurberg (2013), o desenho infantil expressa uma combinação do que elas sabem e gostam de desenhar com suas representações de meio ambiente. Em um trabalho realizado na zona norte do município do Rio de Janeiro, a árvore mais comum nos desenhos de crianças do $6^{\circ}$ ano foi a macieira, uma espécie incomum para a região. Situação semelhante foi observada nos desenhos da turma 600 , também de $6^{\circ}$ ano, onde o elemento árvore foi o mais presente na categoria ambiente preservado, inclusive, com um desenho representando uma macieira (Figura 2B). Na turma 601 as árvores foram representadas em seis desenhos (Figura 2D), enquanto que nos demais, apenas o ambiente físico, água, pedras e montanhas foram representados.

O elemento pedra foi representado em nove desenhos feitos pelos alunos da Escola Manoel Miguel Souto (Figuras 2A e 4A). Esse dado é compatível com a evocação de livre de palavras, pois, esse grupo semântico foi classificado como intermediário ( $2^{-}$quadrante). Como pode ser observado na Figura $1 \mathrm{~A}$, o leito do rio próximo ao distrito de Campelo apresenta inúmeras formações rochosas, as quais em alguns pontos formam "piscinas naturais" que os moradores utilizam para o lazer. Por outro lado, esse elemento não esteve presente em nenhum desenho da turma 601 da Escola Viva, enquanto que na turma 600 foram nove desenhos com esse elemento, ilustrados aqui nas Figuras 2B e 4B.

Figura 2: Desenhos representando o rio Pomba como um ambiente preservado: (A) Escola Manoel Miguel Souto; (B) e (C) Escola Viva, turma 600; (D) Escola Viva, turma 601. 


\section{Ensino, Saúde e Ambiente - V.10 (2), pp. 16-38, Ago. 2017}

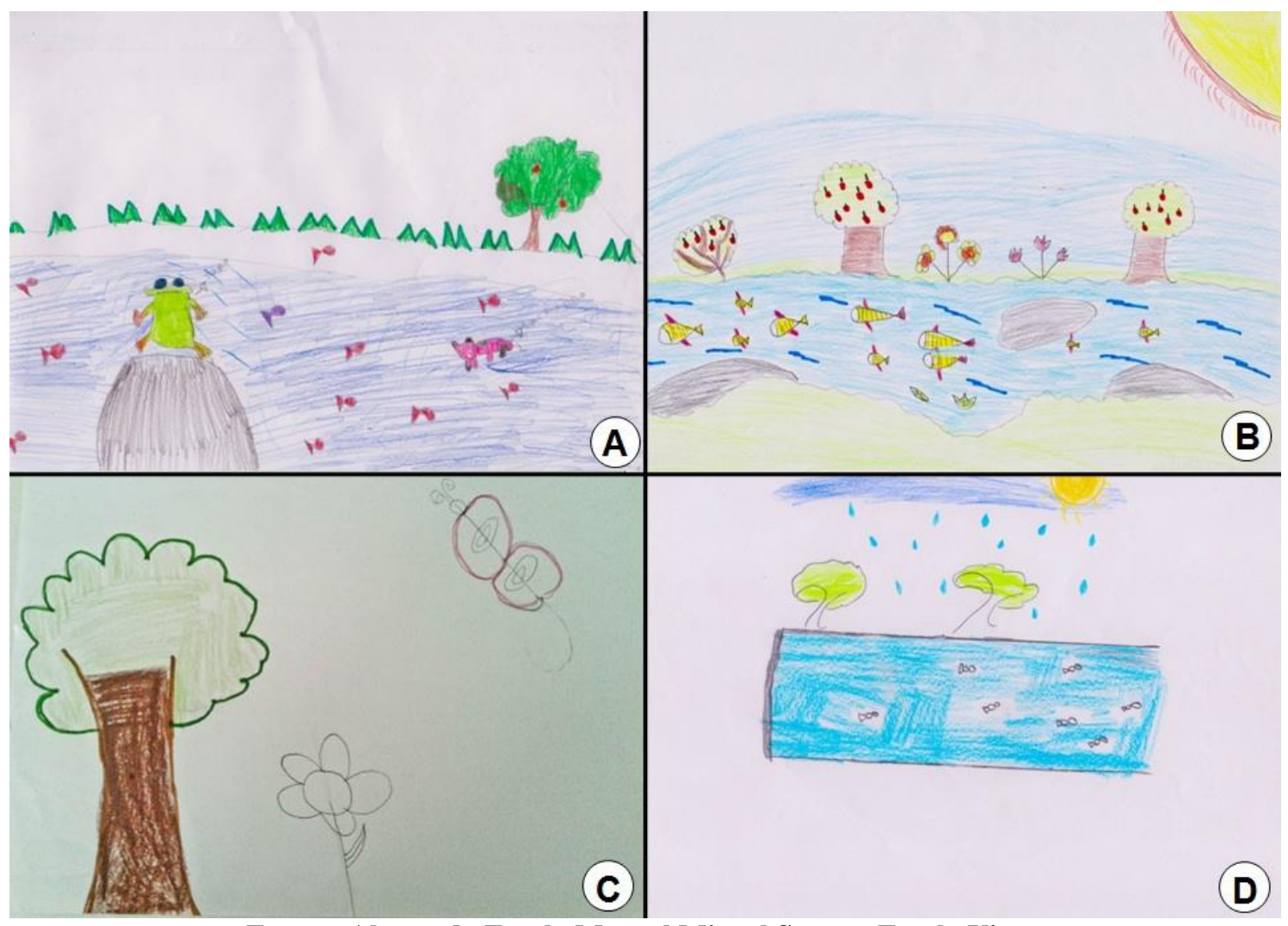

Fontes: Alunos da Escola Manoel Miguel Souto e Escola Viva.

\section{AMBIENTE NÃO PRESERVADO}

Apenas um desenho representou o rio como um ambiente não preservado na Escola Manoel Miguel Souto, caracterizado pela presença de lixo no rio (Figura 3A). No distrito de Campelo há coleta de lixo, porém, não há rede de esgoto, e o mesmo é jogado no rio.

Em ambas as turmas da Escola Viva a presença de garrafas pet, pneus, sacos de lixo e até mesmo TVs jogadas dentro do rio foram os principais elementos presentes nos desenhos na categoria ambiente não preservado (Figuras 3B, C e D). Em dois desenhos, entre eles aquele da Figura 3D foi representado pescadores pescando esses objetos no rio. O lançamento de esgoto também esteve presente nos desenhos, porém em menor freqüência (Figura 3C). A Figura 3B representa uma pessoa jogando o lixo no rio. Essa é uma cena muito comumente observada nas margens do rio. Além de todo e qualquer tipo de lixo, joga-se também móveis velhos, entulhos de obras e animais mortos. A representação social do ambiente não preservado feito pelos alunos de ambas as escolas foi muito fiel a realidade do município. No estudo realizado por Crespo (2012), acerca da opinião pública sobre "o que o brasileiro pensa do meio ambiente e do consumo sustentável", o desmatamento, a poluição de rios, lagos e outras fontes de água, 


\section{Ensino, Saúde e Ambiente - V.10 (2), pp. 16-38, Ago. 2017}

poluição do ar e o lixo foram as principais questões levantadas pela população investigada. Os desenhos feitos pelos alunos dessas turmas estão de acordo com essa tendência nacional.

\section{AMBIENTE CONSTRUÍDO}

A principal representação de elementos construídos nos desenhos feitos pelos alunos da Escola Manoel Miguel Souto foi ponte (Figura 4AC). Esse elemento foi representado em 16 dos 20 desenhos, sendo que 12 desenhos a ponte representada foi a Ponte Raul Veiga (também conhecida como ponte velha ou ponte de arcos) (Figura 1B). Essa ponte é a mais antiga do município e liga seus dois lados separados pelo rio Pomba. Foi construída em 1922, é considerada como um dos principais pontos turísticos e talvez por isso tenha uma elevada representatividade, mesmo para uma comunidade que reside em um distrito distante do centro da cidade. Esses dados contrastam com os dados da evocação livre de palavras, uma vez que o elemento ponte foi evocado apenas uma vez e em quinta posição pelos alunos dessa escola.

Figura 3: Desenhos representando o rio Pomba como um ambiente não preservado: (A) Escola Manoel Miguel Souto; (B) e (C) Escola Viva, turma 600; (D) Escola Viva, turma 601.

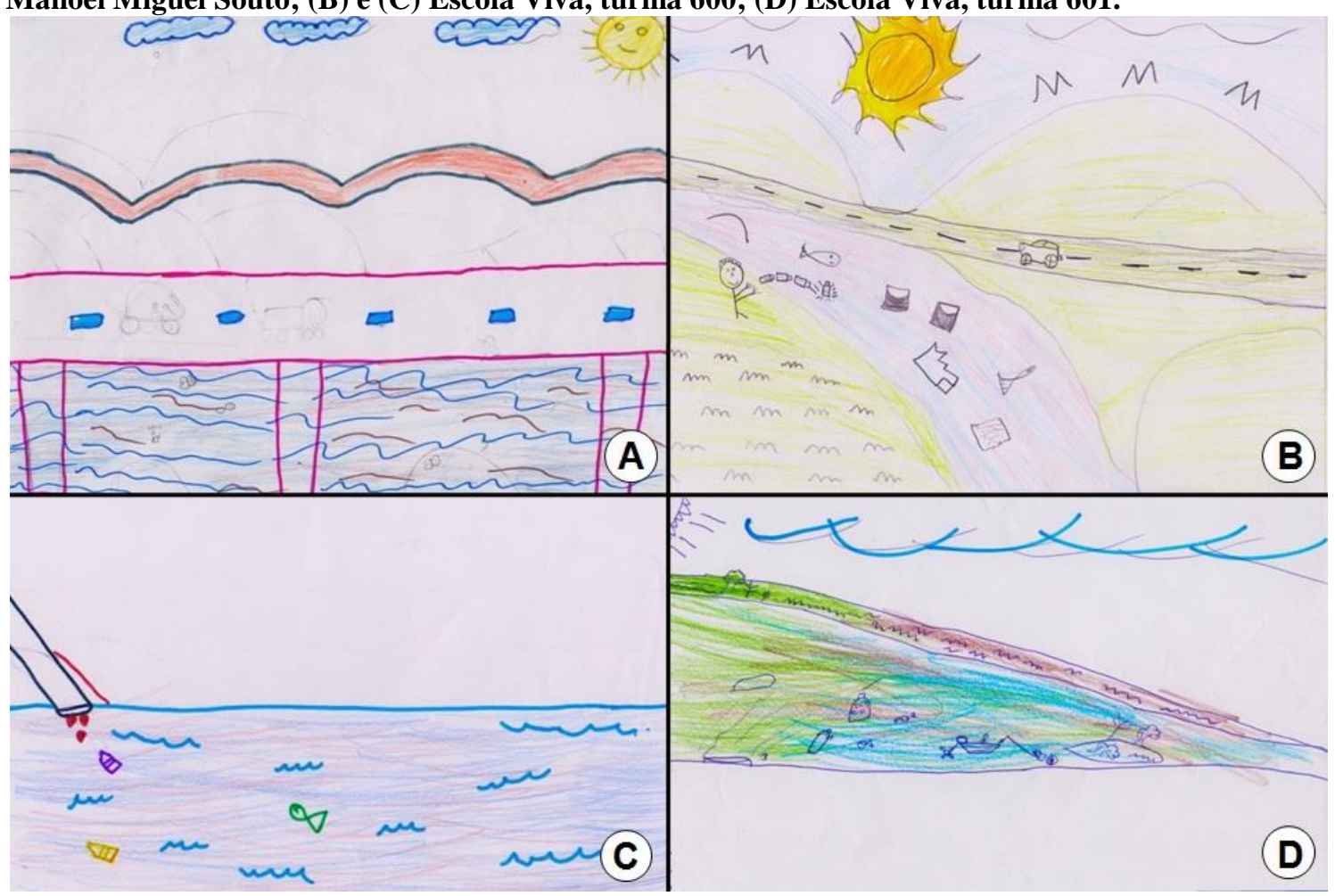

Fontes: Alunos da Escola Manoel Miguel Souto e Escola Viva. 


\section{Ensino, Saúde e Ambiente - V.10 (2), pp. 16-38, Ago. 2017}

Em ambas as turmas da Escola Viva, o elemento ponte também esteve presente nos desenhos. Na turma 600, ponte foi ilustrada em cinco dos seis desenhos (Figura 4B), sendo que em quatro desses desenhos, a Ponte Raul Veiga também foi representada (Figura 1B). Na turma 601, a mesma ponte foi ilustrada em dois desenhos entre os cinco incluídos nessa categoria (Figura 4C), revelando também que para os alunos dessa escola, essa construção humana possui uma representação social importante. Contudo, essa representação foi menor quando comparada com os desenhos da Escola Manoel Miguel Souto. Essa característica encontra respaldo na afirmação de Pereira (2006), onde as crianças desenham menos o que vê e mais o que sabe sobre um objeto. Corroborando essa firmação, Líbera e Jurberg (2013), a partir do estudo de vários autores, afirmam que na faixa etária compreendida entre nove e 14 anos, as crianças desenham não apenas aquilo que veem, mas aquilo que sabem existir. Como citado anteriormente, a Ponte Raul Veiga tem um significado histórico-cultural muito forte entre os cidadãos paduanos, o que faz com que tenha uma importante representação social para eles.

O elemento casa foi raramente representado nos desenhos dos alunos de ambas as escolas. Na Escola Manoel Miguel Souto apenas um desenho, nas turmas 600 e 601 da Escola Viva foram representados em dois e um desenhos, respectivamente. Esses dados contrastam com a realidade do município, pois, com exceção de dois trechos onde há apenas vegetação nas margens do rio, nos demais trechos as edificações são construídas muito próximas as margens, e, em alguns casos, até mesmo invadindo o leito do rio Pomba.

\section{AMBIENTE COMO RECURSO}

Apenas na escola Manoel Miguel Souto foi feitos desenhos que representassem o rio como recurso. Foram três desenhos, sendo dois representando a pesca e um e a extração de areia, representada pela balsa que retira esse recurso do rio (Figura 5). Devido ao anonimato dos desenhos, não foi possível identificar a criança que o construiu, mas pode-se supor que essa atividade é uma importante fonte de recurso financeiro para sua família, uma vez que, segundo Capelle e Munford (2015), o desenho é um signo empregado pela criança constituído pela interação social revela uma realidade por ela conceituada. Essa questão deve ser trabalhada futuramente, pois segundo Sauvé (2005), um dos aspectos da educação ambiental é estimular à conservação da matéria prima do meio ambiente e ao consumo responsável. 


\section{Ensino, Saúde e Ambiente - V.10 (2), pp. 16-38, Ago. 2017}

A figura humana foi pouco representada nos desenhos feitos pelos alunos de ambas as escolas. Na Escola Manoel Miguel Souto, seres humanos foram retratados em cinco desenhos, sendo que em dois desenhos estavam pescando, em outros dois estavam caminhando na margem do rio, e no último desenho apareceram andando de bicicleta e dirigindo automóvel. Segundo Líbera \& Jurberg (2013), a utilização da natureza em favor do homem é recorrente nos desenhos infantis. Em nosso trabalho não percebemos essa representação como um fator relevante, uma vez que em apenas cinco dos 20 desenhos analisados a figura humana foi retratada. Por outro lado, concordamos com as autoras acima quando afirmam que é comum a representação de humanos utilizando a natureza em prol de necessidades e lazer. No distrito de Campelo é comum a pesca como fonte de alimento e lazer.

Figura 4: Desenhos representando o rio Pomba como um ambiente construído: (A) Escola Manoel Miguel Souto; (B) Escola Viva, turma 600; (C) e (D) Escola Viva, turma 601.

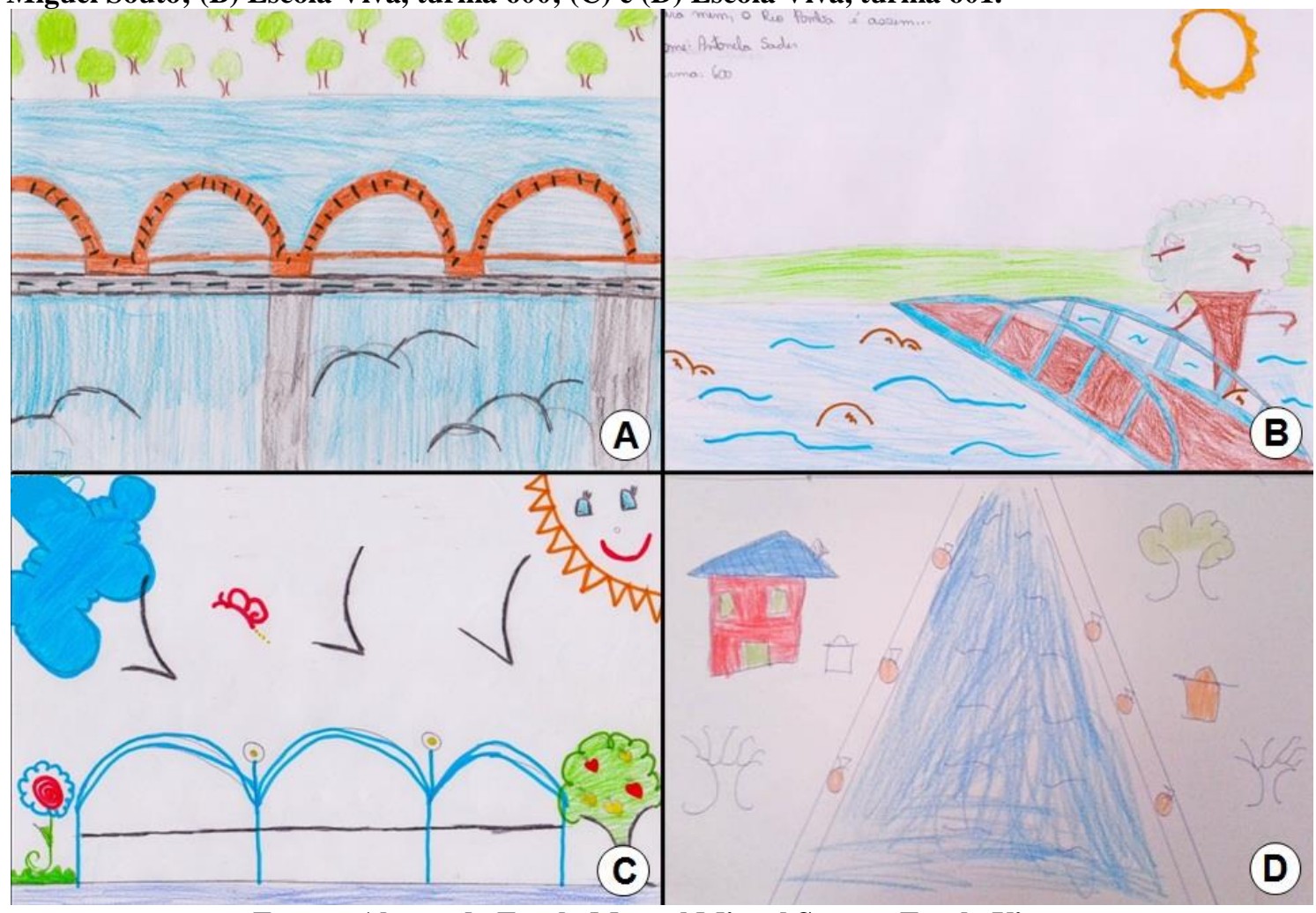

Fontes: Alunos da Escola Manoel Miguel Souto e Escola Viva.

Figura 5: Desenho representando o rio Pomba como recurso. 


\section{Ensino, Saúde e Ambiente - V.10 (2), pp. 16-38, Ago. 2017}

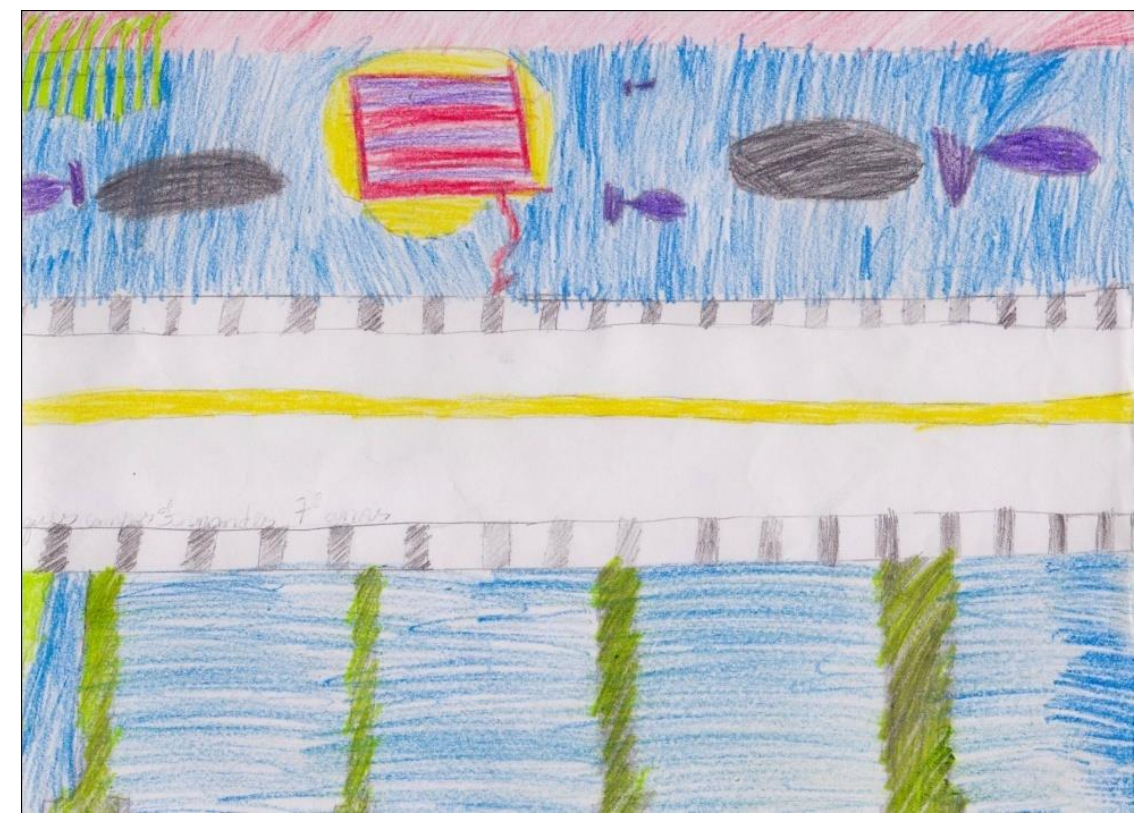

Fonte: Aluno da Escola Manoel Miguel Souto.

$\mathrm{Na}$ turma 600 da Escola Viva, a figura humana foi representada em apenas dois desenhos, e, em ambos estavam jogando lixo no rio. Na turma 601, os humanos foram representados como pescadores. Em um desenho são duas figuras humanas onde uma está pescando um "pneu" e o outro pescador está pescando uma "garrafa pet". No outro desenho o pescador pesca um objeto que não conseguimos identificar exatamente, contudo, nitidamente não é um peixe. Reigota (2010) também observou que o ser humano foi uma nota dissonante do meio ambiente em um grupo de professores do município de Guarapuava/PR. Em seu trabalho, o autor classificou o homem como um depredador do meio ambiente. No presente trabalho, essa representação também ficou bem evidente na representação dos alunos da Escola Viva de ambas as turmas pesquisadas. Será essa representação dos alunos um reflexo da representação dos professores? Essa questão deve ser investigada futuramente.

A pequena representatividade do ser humano interagindo com o rio Pomba observada nesse trabalho está de acordo com os dados citados por Rezler et al. (2009). As autoras pesquisaram 66 alunos da quinta e sexta séries do ensino fundamental em Rolândia/PR, e em apenas dez desenhos a figura do ser humano foi representada. As representações citadas pelas autoras tais como humanos utilizando o ambiente como lazer, depredador e poluidor do ambiente, são semelhantes aquelas observadas no presente trabalho. A pequena representação da figura humana no contexto do presente trabalho está de acordo com as observações de Reigada e Reis (2004) e Garrido e Meirelles (2014), onde relataram que ambiente para crianças entre seis e 11 anos é 


\section{Ensino, Saúde e Ambiente - V.10 (2), pp. 16-38, Ago. 2017}

composto apenas elementos naturais como árvores, flores e animais. Mais recentemente, e nessa mesma direção, Godois et al. (2013) afirmaram que é comum os indivíduos não se considerarem como parte da natureza.

A análise da representação social dos animais nos desenhos está demonstrada na Tabela 6. A principal representação da fauna do rio Pomba foi o grupo peixe. Na Escola Manoel Miguel Souto, a freqüência dos peixes nos desenhos é coerente com a evocação livre de palavras, pois, esse grupo semântico foi o mais evocado e em posições superiores, localizando-o no núcleo central (Tabelas 1 e 2). Por outro lado, na Escola Viva, esse grupo semântico foi classificado como elemento intermediário $\left(3^{\circ}\right.$ quadrante) (Tabelas 3 e 4), o que contrasta com sua freqüência nos desenhos, sobretudo, na turma 601 (Tabela 6). Cabe ressaltar a presença de um animal semelhante a uma tartaruga, e que talvez possa representar o cágado-de-Hoge [Mesoclemmys hogei (Mertens, 1967)], também conhecido por cágado-de-Hogei ou cágado-do-Paraíba, uma espécie de quelônio ameaçado de extinção, e que outrora foi muito abundante nos rios Pomba e Paraíba do sul.

Tabela 6: Frequência de animais nos desenhos dos alunos das Escolas Manoel Miguel Souto (EMMS) e na Escola Viva (EV), turmas 600 e 601 .

\begin{tabular}{lccc}
\hline \multirow{2}{*}{ Animais } & \multicolumn{3}{c}{ Escolas } \\
\cline { 2 - 4 } & EMM & EV/600 & EV/601 \\
& S & & 03 \\
\hline Borboleta & - & 02 & 14 \\
Peixe & 11 & 07 & - \\
Sapo & 01 & - & - \\
Tartaruga & - & 01 & - \\
Aves & 01 & 02 & - \\
Cachorro & 01 & - & 17 \\
\hline Total & 14 & 12 & \\
\hline
\end{tabular}

Fonte: Os autores.

Frazão et al. (2010) analisaram a percepção de professores e alunos em relação a preservação das tartarugas marinhas na Praia de Pipa/RN. Os autores observaram por meio de desenhos que os alunos não têm clareza da importância do local para a preservação das tartarugas marinhas. Concluíram que há uma carência por parte dos alunos de informações sobre as tartarugas marinhas. Podemos observar situação semelhante entre os alunos das duas escolas que participaram do presente trabalho. Com 


\section{Ensino, Saúde e Ambiente - V.10 (2), pp. 16-38, Ago. 2017}

exceção dos peixes, os alunos não vêem o rio Pomba como um ambiente rico em biodiversidade. Crespo (2012) informou que metade dos brasileiros tem conhecimento ou já ouviu falar sobre a destruição da biodiversidade, e outra metade desconhece o tema. Entre aqueles que ouviram falar, $86 \%$ afirmaram que os rios fazem parte da biodiversidade.

\section{CONSIDERAÇÕES FINAIS}

Os dados obtidos a partir da análise da evocação livre de palavras e dos desenhos livres demonstraram uma visão dicotômica na representação social do rio Pomba entre os alunos da Escola Manoel Miguel Souto (EMMS) e Escola Viva (EV). Essa dicotomia pode ser um reflexo da localização geográficas das escolas, enquanto a primeira situa-se na zona rural e a segunda na zona urbana. Esse aspecto será investigado em projetos futuros que serão desenvolvidos nas escolas.

Os elementos naturais possuem maior representação para os alunos da EMMS, indicando que para eles o rio é sinônimo de natureza conservada. Na evocação livre de palavras a poluição foi um elemento periférico, e nos desenhos o ambiente não preservado foi representado por apenas um aluno, demonstrando que a degradação do rio possui pouca representatividade para os alunos dessa escola.

Por outro lado, na E.V. a principal representação social do rio foi a poluição. Esse aspecto figurou como elemento do núcleo central na evocação livre de palavras e foi frequentemente desenhado pelos alunos, sobretudo, na turma 601.

Esses dados encontram respaldo na concepção de Reigota (1991), onde para o autor o conceito de ambiente é uma representação social, principalmente, em função do grupo social que o utiliza. Os alunos da Escola Manoel Miguel Souto utilizam o rio Pomba para o lazer e subsistência (extração de areia e pesca), portanto, suas representações enquadram-se nas categorias naturalista (evidencia somente os aspectos naturais, sendo o meio ambiente sinônimo de natureza intocada) e antropocêntrica (enfatiza a utilidade dos recursos naturais para a sobrevivência do ser humano). Na Escola Viva, as representações enquadraram-se na categoria globalizante (evidenciada pelas relações recíprocas entre natureza e sociedade em interações sociais, biofísicas, políticas, filosóficas e culturais), nesse caso, caracterizado pela poluição do rio.

Completando essa ideia, Reigota (1999) reforça que não se transmite conhecimentos sobre meio ambiente sem antes conhecer essas representações e colocá- 


\section{Ensino, Saúde e Ambiente - V.10 (2), pp. 16-38, Ago. 2017}

las em discussão. Dessa forma, a obtenção das representações sociais dos alunos do ensino fundamental de ambas as escolas pesquisadas foi um passo importante para traçar metas e estratégias para futuros projetos de educação ambiental nas escolas pesquisadas.

\section{AGRADECIMENTOS}

Os autores agradecem a Direção, corpo docente e alunos de ambas as escolas pela participação voluntária e valiosa para a realização desse trabalho; a Divisão de Prática Discente/UFF, pela concessão das bolsas para as Discentes do Curso de Licenciatura em Ciências Naturais/INFES/UFF; e ao Professor Pablo de Vargas Guimarães (INFES/UFF), pela cessão da fotografia da Figura 1B.

\section{REFERÊNCIAS}

BARROS, A.P.; BARATA, M.M.L. Concepções de alunos do ensino médio em uma comunidade do entorno do aterro sanitário (as) de Paciência, RJ: aplicação do projeto La Main À La Pate. Revbea. v. 4, p. 160-169, 2009.

BEZERRA, T.M.O.; FELICIANO, A.L.P.; ALVES, A.G.C. Percepção ambiental de alunos e professores do entorno da Estação Ecológica de Caetés - Região Metropolitana do Recife-PE. Biotemas. v. 21, 1, p. 147-160, 2008.

BRASIL. Ministério da Educação e do Desporto. Secretaria de Ensino Fundamental. Parâmetros curriculares nacionais: meio ambiente. Brasília: MEC/SEF, 1997. 76 p. Disponível em http://portal.mec.gov.br/seb/arquivos/pdf/meioambiente.pdf. Acessado em 20 de fevereiro de 2017.

CAPPELLE, V.; MUNFORD, D. Desenhando e escrevendo para aprender ciências nos anos iniciais do ensino fundamental. Alexandria. v.8, n.2, p.123-142, 2015.

CAPRA, F. A teia da vida. São Paulo: Cultrix, 1998.

CORTES JUNIOR, L.P.; CORIO, P.; FERNANDEZ, C. As representações sociais de química ambiental dos alunos iniciantes na graduação em Química. Química Nova na Escola. v. 31, n. 1, p. 46-54, 2009.

CRESPO, S. 2012. O que o brasileiro pensa do meio ambiente e do consumo sustentável. Disponível em http://www.em.ufop.br/ceamb/petamb/cariboost_files/ ma.pdf. Acessado em 07 de fevereiro de 2017.

FERREIRA, V.C.P.; SANTOS JÚNIOR, A.F.; AZEVEDO, R.C.; VALVERDE, G. A representação social do trabalho: uma contribuição para o estudo da motivação. Estação Científica. n. 1, p. 1-13. 2005.

FRAZÃO, J.O.; SILVA, J.M.; CASTRO, C.S.S. Percepção ambiental de alunos e professores na preservação das tartarugas marinhas na praia de Pipa - RN. Rev.

eletrônica Mestr. Educ. Ambient. v. 24, p. 156-172, 2010. 


\section{Ensino, Saúde e Ambiente - V.10 (2), pp. 16-38, Ago. 2017}

GALLO, S. Transversalidade e educação: pensando uma educação não-disciplinar. In: ALVES, N.; GARCIA, R.L. (Orgs.). O Sentido da Escola. Rio de Janeiro: DP \& A, 2000.

GALVÃO, D.F.; DICTORO, V.P.; TIMOTEO, C.K.; COLENCI, P.L. Representação social da água e sensibilização ambiental de estudantes do $6^{\circ}$ ano de uma escola pública em São Carlos (SP). Revbea. v. 11, n. 2, p. 91-117. 2016.

GARRIDO, L.S.; MEIRELLES, R.M.S. Percepção sobre meio ambiente por alunos das séries iniciais do Ensino Fundamental: considerações à luz de Marx e de Paulo Freire. Ciênc. Educ. v. 20, n. 3, p. 671-685, 2014.

GODOIS, L.R.; MOURA, A.C.P.; SALLA, V.P.; LIMA, D.M.; AMARAL, A.Q. Representações sociais de meio ambiente de alunos na trilha ecológica da UTFPR-DV. XIV Encontro Paranaense de Educação Ambiental. Cascavel, PR, Brasil - 01 a 04 de outubro de 2013.

LÍBERA, B.D.; JURBERG, C. Ei, aluno do $6^{\circ}$ ano: para você, o que é meio ambiente? Revista Metáfora Educacional. n. 15, p.149-170, 2013.

LUTZEMBERG, J.A. O fim do futuro? Manifesto ecológico brasileiro. Porto Alegre: Movimento, 1980.

MAGALHÃES JÚNIOR, C.A.O.; TOMANIK, E.A. Representações sociais e direcionamento para a educação ambiental na reserva biológica das Perobas, Paraná. Investigações em Ensino de Ciências. v. 17, n. 1, p.227-248. 2012.

MAGALHÃES JÚNIOR, C.A.O.; TOMANIK, E.A. Representações sociais de meio ambiente: subsídios para a formação continuada de professores. Ciência \& Educação. v. 19, n. 1, p. 181-199. 2013.

MAZZOTTI, T.B. Representação social de "problema ambiental”: uma contribuição à educação ambiental. R. bras. Est. pedag. Brasília, v. 78, n. 188/189/190, p. 86-123, jan./dez., 1997.

PEREIRA, L.T.K. O desenho infantil e a construção da significação: um estudo de caso. In: World Conference on Arts Education: Building Creative Capacities for the 21st Century - UNESCO, Lisboa, v. 01, 2006, 19 p. Disponível em: http://portal.unesco.org/ culture/en/files/29712/11376608891lais-krucken-pereira.pdf/lais-krucken-pereira.pdf. Acessado em 06 de fevereiro de 2017.

PEREIRA, P.S.; PEREIRA, A.M.B.; CASTRO, C.L.F. Percepção dos moradores sobre a poluição do rio Cariús, município de Farias Brito, Ceará. Revista Eletrônica em Gestão, Educação e Tecnologia Ambiental. v. 20, n. 1, p. 363-371, 2016.

REIGADA, C.; REIS, M.F.C.T. Educação ambiental para crianças no ambiente urbano: uma proposta de pesquisa-ação. Ciência \& Educação. v. 10, n. 2, p. 149-159, 2004.

REIGOTA, M. O meio ambiente e suas representações no ensino de ciências em São Paulo - Brasil. Uniambiente. Boletim da Comissão Interinstitucional sobre Meio Ambiente e Educação Universitária. n. 1, p. 27-30, 1991.

REIGOTA, M. A floresta e a escola: por uma educação ambiental pós-moderna. São Paulo: Cortez 1999.

REIGOTA, M. Meio ambiente e representação social. Série: Questões da nossa época. 8ª edição. São Paulo: Cortez, 2010. 
Ensino, Saúde e Ambiente - V.10 (2), pp. 16-38, Ago. 2017

REZLER, M.A.; SALVIATO, G.M.S.; WOSIACKI, S.R. Quando a imagem se torna linguagem de comunicação de estudantes da $5^{\mathrm{a}}$ e $6^{\mathrm{a}}$ séries do ensino fundamental em Educação Ambiental. Revista Electrónica de Enseñanza de las Ciencias. v. 8, n. 1, p. 304-325, 2009.

ROOS, A.; BECKER, E.L.S. Educação ambiental e sustentabilidade. Revista Eletrônica em Gestão, Educação e Tecnologia Ambiental. v. 5, n. 5, p. 857-866, 2012.

SAUVÉ, L.; ORELLANA, I. A. A formação continuada de professores em Educação Ambiental: a proposta do EDAMAZ. In: SATO, M.; SANTOS, J. E. (Orgs.). A contribuição da Educação Ambiental à esperança de Pandora. São Carlos: RIMA. 2001.

SAUVÉ, L. Educação Ambiental: possibilidades e limitações. Educação e Pesquisa. São Paulo, v. 31, n. 2, p. 317-322, mai./ago. 2005.

SILVA, S.N. Concepções e representações sociais de meio ambiente: uma revisão crítica da literatura. VII Encontro Nacional de Pesquisa em Educação em Ciências. Florianópolis, SC, 2009.

SILVA, M.J.; SILVA, G.C.; TREVISAN, I. Representações sociais de meio ambiente: um estudo com licenciandos de diferentes cursos da UEPA, Campus Altamira.

Amazônia - Revista de Educação em Ciências e Matemática. v. 11, n. 21, p. 92-105, 2014.

SILVA, L.F.; TEIXEIRA, E.S. A educação para a sustentabilidade: representações de educação ambiental em docentes de formação de professores. Revista de Ciências

Humanas - Educação. v. 16, n. 27, p. 07-21, 2015. 